593

\section{ABNORMAL TROPONIN AND COAGULATION AND RENAL INDICES MAY INDICATE RECENT INSULT IN INFANTS WITH NEONATAL BRAIN INJURY}

\section{S. Smith ${ }^{1}$, A. Delany ${ }^{1}$, A. Walsh ${ }^{1}$, A. Twomey ${ }^{1}$, V. Donoghue ${ }^{2}$, E. Molloy ${ }^{1}$ \\ ${ }^{1}$ Neonatology, ${ }^{2}$ Radiology, National Maternity Hospital Holles Street, Dublin, Ireland}

Objective: Troponin $\mathrm{CK}$ and $\mathrm{LDH}$ are sensitive markers of tissue damage sustained in global hypoxia-ischemia. THis study aims to examine the relationship between Troponin-T, coagulopathy, CK, $\mathrm{LDH}$, creatinine and neuroimaging in infants with neonatal encephalopathy and coagulopathy.

Methods: Serum troponin was sampled in infants requiring resuscitation at birth and/or neonatal encephalopathy in a tertiary referral neonatal centre from July 2006-October 2009. Infants with congenital defects, evidence of infection and maternal drug addiction were excluded from the study. Infants were retrospectively divided into those with normal and abnormal troponin. Birth history, biochemical parameters and brain imaging were evaluated.

Results: 37 infants with neonatal encephalopathy had troponin CK LDH and coagulation screening. Infants with an elevated troponin $(n=16)$ had significantly increased PT and APTT and creatinine compared with infants with a normal troponin $(n=21)$ (Table 1). Five infants in the normal troponin group had normal cerebral imaging compared with two in the raised troponin group. (Cranial ultrasound and/ or MRI).

\begin{tabular}{|c|c|c|c|c|c|c|c|c|}
\hline $\begin{array}{l}\text { Tropo- } \\
\text { nin }\end{array}$ & $\begin{array}{l}\text { Tro-po- } \\
\text { nin }\end{array}$ & $\begin{array}{l}\text { Pro- } \\
\text { throm- } \\
\text { bin } \\
\text { time } \\
\text { (PT) }\end{array}$ & $\begin{array}{l}\text { Activated } \\
\text { Partial } \\
\text { Thrombo- } \\
\text { plastin } \\
\text { Time } \\
\text { (APTT) }\end{array}$ & $\begin{array}{l}\text { Fibri- } \\
\text { nogen }\end{array}$ & $\begin{array}{l}\text { Crea- } \\
\text { tinine } \\
\text { kinase } \\
\text { (CK) }\end{array}$ & $\begin{array}{l}\text { Lactate } \\
\text { dehydro- } \\
\text { genase } \\
(\mathrm{LDH})\end{array}$ & $\begin{array}{l}\text { Maxi- } \\
\text { mum } \\
\text { Crea- } \\
\text { tinine }\end{array}$ & $\begin{array}{l}\text { MRI } \\
\text { Nor- } \\
\text { mal }\end{array}$ \\
\hline $\begin{array}{l}\text { Abno- } \\
\text { rmal } \\
n=16\end{array}$ & $\begin{array}{l}0.34+/- \\
0.23\end{array}$ & $\begin{array}{l}20.1+/- \\
9.7\end{array}$ & $\begin{array}{l}38+/- \\
12.8\end{array}$ & $\begin{array}{l}1.62+/- \\
0.78\end{array}$ & $\begin{array}{l}4278+/- \\
6718\end{array}$ & $\begin{array}{l}2816+/- \\
3772\end{array}$ & $\begin{array}{l}143.81 \\
+/- \\
59.14\end{array}$ & 2 \\
\hline $\begin{array}{l}\text { Nor- } \\
\text { mal } \\
n=21\end{array}$ & $\begin{array}{l}0.055+/- \\
0.048\end{array}$ & $\begin{array}{l}14.0+/- \\
2.6\end{array}$ & $\begin{array}{l}31.7+/- \\
3.86\end{array}$ & $\begin{array}{l}1.95+/- \\
0.88\end{array}$ & $\begin{array}{l}1278+/- \\
805\end{array}$ & $\begin{array}{l}1070+/- \\
742\end{array}$ & $\begin{array}{l}100.76 \\
+/- \\
41.10\end{array}$ & 5 \\
\hline $\begin{array}{l}p \\
\text { value }\end{array}$ & 0.019 & 0.007 & 0.03 & 0.24 & 0.048 & 0.058 & 0.013 & $\begin{array}{l}\text { Not } \\
\text { appli- } \\
\text { cable }\end{array}$ \\
\hline
\end{tabular}

[Normal vs abnormal troponin]

Conclusions: Infants with brain injury on MRI or cranial ultrasound following perinatal asphyxia who have elevated troponin may also be coagulapathic. Infants with elevated troponin are more likely to have abnormalities on MRI. In the current context of therapeutic hypothermia it is crucial to evaluate multisystem involvement in infants with neonatal encephalopathy.

594

\section{EARLY PREDICTION OF LONG TERM OUTCOME OF LOW RISK PREMATURE NEONATES WITH THE AEEG}

\author{
V. Soubasi, K. Mitsakis, K. Sarafidis, M. Griva, \\ E. Agakidou, E. Diamanti, V. Drossou
}

1st Department of Neonatology, Aristotle University of Thessaloniki, Thessaloníki, Greece

Background and aims: Preterm infants of lower gestational age(GA) display advanced maturation of aEEG in comparison to others of higher GA at the same post conceptional age(PCA). Brain ontogeny follows specific developmental stages and any deviations from this process may influence later cognitive function.

To investigate the association between aEEG evolution during the neonatal period and outcome of premature infants with different GA.

Methods: 84 clinically stable preterm infants(GA 26-32 wks) without ultrasonographic evidence of neurological abnormalities at birth were assessed at the age of 3 years (Bayleys screening test, III edition). aEEG traces of all neonates were recorded within the first $72 \mathrm{~h}$ of life and then weekly until discharge. Four aspects of each tracing (continuity,sleep-wake cycling, bandwidth, and amplitude of the lower border)were evaluated applying pre-established criteria.

Results: None of the children had gross motor disturbances, but one, and severe developmental delays. The children were divided into group $A$ $(n=23$, mild developmental problems) and group $B(n=61$ normal for the age). Both groups had comparable initial neonatal characteristics. Group A showed higher scores in all 4 components of the aEEG as compared to group $B$, with significant differences around 31-32 wks PCA. Total score(T) of the 4 aspects of aEEG was significantly higher between 28-32wks (figure). 


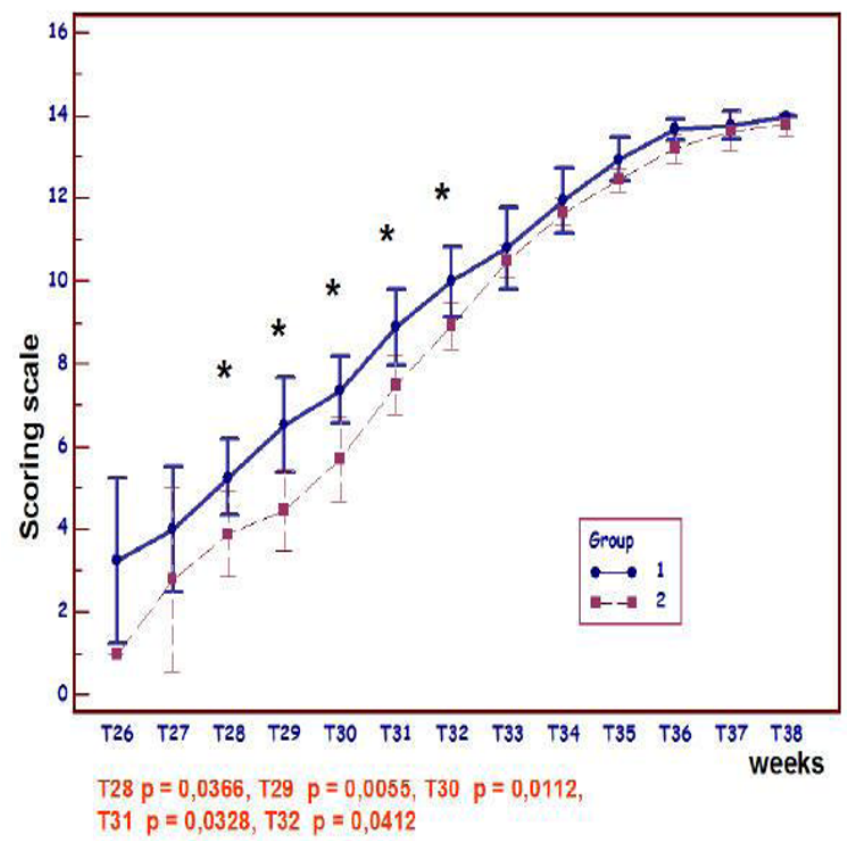

[figure]

Conclusions: Accelerated maturation of cerebral function seems to be associated with long-term cognitive and behavioral deficits without overt effects on motor development in preterm infants who were neurologically normal in the neonatal period.

595

\section{CORRELATION BETWEEN ULTRASOUND TEXTURE ANALYSIS OF THE CEREBELLUM AND STANDARD DIAGNOSIS OF WHITE MATTER DAMAGE IN PRETERM NEONATES}

E. Bonet-Carne ${ }^{1}$, V. Tenorio ${ }^{2,3,4}$, A. Arranz ${ }^{2,3,4}$, I. Amat-Roldan ${ }^{3,4}$, E. Gratacos $2,3,4$

${ }^{1}$ Transmural Biotech, SL, ${ }^{2}$ Maternal-Fetal and Neonatology Departments, Institut Clinic of Gynecology, Obstetrics and Neonatology, Hospital Clinic-Universidad de Barcelona, ${ }^{3}$ Fetal and Perinatal Medicine Research Group, Institut d'Investigacions Biomèdiques August Pi i Sunyer (IDIBAPS), ${ }^{4}$ Centro de Investigación Biomédica en Red de Enfermedades Raras (CIBER-ER), Instituto de Salud Carlos III, Barcelona, Spain

Background and aims: Ultrasound diagnosis of white matter damage (WMD) is still subject to variability, and methods based on quantitative ultrasound analysis are under investigation to improve diagnostic accuracy. The correlation between WMD and cerebellar changes in term and one-year old infants has previously been described. We tested the hypothesis that a semiautomated method for ultrasound texture analysis (AQUA) could detect patterns to predict the standard clinical diagnosis of WMD in preterm neonates.

Methods: A cohort of 40 very preterm infants ( $<32$ weeks) underwent 2 cranial US scans within the first and after 2 weeks of life. WMD was diagnosed using standard criteria. Texture analysis was run in the cerebellum, manually delineated in a coronal plane through the anterior fontanelle. A classification algorithm based on texture coefficients was used to correlate to clinical diagnosis and its ability to predict in the first scan a later diagnosis of WMD was then evaluated.

Results: Median gestational age was $29+4$ weeks $(26+0-31+6)$. WMD was diagnosed in 10/40 infants. Cerebellar texture analysis in the first scan could identify cases later diagnosed with PVL with a sensitivity of $100 \%$ and an accuracy of $95 \%$, after adjustment for gestational age and birth weight.

Conclusions: The cerebellum might contain useful information that improves the prediction of standard white matter damage diagnosis. These preliminary data support further investigation of the role of this brain structure in the neonatal diagnosis of WMD by means of semi-automated quantitative ultrasound analysis.

\section{6}

MRI OF THE BRAIN OF TWINS WITH TWIN TWIN TRANSFUSION SYNDROME. (TTTS)
A. Lyons ${ }^{1}$, M. Boyle 1 , A. Foran', S. Ryan ${ }^{2,3}$
${ }^{1}$ Neonatology, ${ }^{2}$ Radiology, Rotunda Maternity Hospital, ${ }^{3}$ Radiology, Children's University Hospital, Dublin, Ireland

Introduction: Perinatal mortality and morbidity rates are higher in twins than in singletons. Monochorionic twins have a high risk of low birth weight, preterm delivery and neurologic morbidity. TTTS occurs as a serious complication in 10 to $15 \%$ of monochorionic diamniotic (MCDA) pregnancies. The assessment of term corrected MRI brain has not been investigated to the best of our knowledge in this specific area to date.

Objective: The aim of this study was to evaluate term corrected MRI brain as a surrogate short-term marker for neonatal outcome of twins with TTTS.

Study Design: We conducted a prospective trial in the Rotunda hospital which had ethical approval. We 